\title{
BREVES APONTAMENTOS SOBRE UM REPOSITÓRIO DIGITAL BILINGUE (PORTUGUES-LIBRAS): o caso do repositório digital Huet
}

\author{
BRIEF NOTES ABOUT A DIGITAL BILINGUAL REPOSITORY \\ (PORTUGUESE-BRAZILIAN SIGN LANGUAGE): \\ The case of the Huet digital repository
}

Rodrigo Oliveira de Paiva ${ }^{1}$ Alegria Benchimol Tania Chalhub ${ }^{3}$

Cassia Cordeiro Furtado ${ }^{4}$

\begin{abstract}
RESUMO
Considerando que atualmente vive-se em um contexto, no qual a internet aparece como uma das peças fundamentais para o acesso a informações, observa-se o caso dos repositórios como espaços em que usuários com características diversas podem acessar conteúdos de seus interesses, de modo sistematizado. Um desses usuários são os surdos, que serão tidos nesta investigação como personagens de estudo pertencentes a uma minoria linguística. Com isso, objetiva-se mostrar como um ambiente informacional digital pode ser projetado para atender aos surdos. Para tanto, procede-se a um estudo de caso com o Repositório digital Huet, tendo um enfoque bibliográfico e descritivo para compreender o funcionamento e estrutura deste ambiente, assim como questões teóricas relacionadas a ele, tais como, o surdo e repositórios digitais. Desse modo, observa-se que o repositório Huet é relevante para as análises em acessibilidade digital de surdos, apesar de algumas alterações e revisões em sua estrutura possam estar em curso, devido ao seu pouco tempo de implantação, principalmente, no que tange ao olhar bilíngue, à arquitetura do ambiente e às condições de acesso e uso com caráter digital inclusivo. Os resultados apontam que, o funcionamento deste repositório vai muito além de somente incluir os surdos por meio de suas vertentes sensoriais e linguísticas em ambientes digitais, mas sobretudo, possibilitam autonomia e experiências agradáveis para o encontro dos conteúdos que este tipo de público almejam/necessita.
\end{abstract}

Palavras-chave: Surdo. Repositório digital Huet. Inclusão digital. Acessibilidade.

\begin{abstract}
Considering that we are currently inserted in a context, in which the internet appears as one of the fundamental pieces for the access to information, it is observed the case of the repositories as spaces in which users with diverse characteristics can access contentes of their interests, in a systematized way. One of these users is the deaf, who will be considered in this investigation as study characters belonging to a linguistic minority. Therefore, it aims to show how a digital information environment can be designed to reach the deaf people. For reaching this goal, a case study over the Huet Digital Repository was carried out, following a bibliographic and descriptive approach to understand the operation and structure of this environment, as well as theoretical issues related to it, such as the deaf people and digital repositories. Thus, it can be observed that the Huet repository is relevant for the analysis of the digital accessibility of the deaf people, although some changes and revisions in their structure may be in progress, due to their short time of implantation, mainly, concerning the bilingual view, the environment architecture and the conditions of access and use with an inclusive digital character. The results point out that the functioning of this repository goes far beyond just including the deaf through their sensorial and linguistic aspects in digital environments, but above all, they allow autonomy and pleasant experiences to reach the content that is aimed and/or needed by this audience.
\end{abstract}

Keywords: Deaf. Huet digital Repository. Digital inclusion. Accessibility.

Artigo recebido em 16/01/2019 e aceito para publicação em 24/02/2019

1 Graduado pela Universidade Federal do Pará, Brasil. Mestrando no Programa de Pós-Graduação em Ciência da Informação da Universidade Federal do Pará, Brasil. Técnico do Ministério da Ciência, Tecnologia, Inovações e Comunicações no Serviço de Biblioteca do Museu Paraense Emílio Goeldi, Brasil. E-mail: rodrigopaiva@museu-goeldi.br.

2 Doutora em Ciência da Informação pelo convênio Instituto Brasileiro de Informação em Ciência e Tecnologia e Universidade Federal do Rio de Janeiro, Brasil. Docente Permanente do Programa de Pós-Graduação em Ciência da Informação da Universidade Federal do Pará, Brasil. Tecnologista Pleno Senior do Museu Paraense Emílio Goeldi, Brasil. E-mail: alegria.benchimol@gmail.com.

3 Doutora em Social Work pela University of Minnesota, Estados Unidos. Professora Adjunta no Núcleo de Educação Online do Instituto Nacional de Educação de Surdos, Brasil. E-mail: chalhubtania@gmail.com.

4 Doutora em Informação e Comunicação em Plataformas Digitais, pela Universidade de Aveiro e Universidade do Porto, em Portugal Líder do Núcleo de Pesquisa Interdisciplinar em Leitura, Comunicação e Design de Hipermídia da Universidade Federal do Maranhã, Brasil. E-mail: cassia.furtado@ufma.br. 


\section{INTRODUÇÃO}

Com a popularização da internet através de diversos suportes de informação, verifica-se a inserção neste cenário de personagens que por muito tempo ficaram à margem da sociedade no que se refere à absorção democrática de conhecimento. Um desses grupos é o dos surdos. Para Alves (2014), a internet é amplamente utilizada por esse grupo, porém o compartilhamento de informações entre esses usuários não ocorre de modo pleno, pois para que isso ocorra é necessária a presença de conteúdos de forma imagéticas para melhor absorção de informações. Além disso, a autora ainda comenta que a percepção visual dos surdos é considerada mais avançada em relação aos ouvintes. Esse fator torna-se relevante, uma vez que precisa ser melhor trabalhado na web visando à inclusão desse grupo.

Tendo em vista a explosão digital que a humanidade enfrenta decorrente da vertiginosa disponibilização de conteúdos informacionais na web, torna-se difícil a empreitada de registrar, organizar e recuperar esse conhecimento com 0 intuito de facilitar 0 acesso a todos os públicos.

Diante desse panorama, tem-se 0 ambiente informacional digital dos repositórios que visam a atender as necessidades informacionais de grupos distintos. Dentre os repositórios, destaca-se 0 Repositório digital Huet do Instituto Nacional de Educação de Surdos (INES). Ele é o primeiro no Brasil com materiais bilíngues, em Língua Brasileira de Sinais (LIBRAS) e português, o que o torna elemento ímpar para a discussão dessa temática.

Desse modo, o objetivo dessa investigação é mostrar como um ambiente informacional digital pode ser projetado para atender aos surdos. Para isso, salienta-se o caso do Repositório digital Huet, dando uma característica de estudo de caso a essa investigação, com elementos de pesquisa bibliográfica e descritiva.

\section{SURDO E A INTERNET}

No transcurso histórico da humanidade, todos que eram diferentes da maioria eram discriminados. Com a população surda esse fato não foi diferente, dado que eles eram alvo de preconceito e até mesmo marginalizados e perseguidos. Ao longo da história as batalhas em que as pessoas surdas enfrentaram deram origens a legislações que são respostas a toda as exclusões por elas sofridas. Muitas foram até segregadas do convívio social, por serem vistas como inferiores intelectualmente. 
Pensando nisso, Rosa e Cruz (2001) relatam um ponto importante sobre a "diferença", que é o fato de ela possuir características próprias o que gera efeitos específicos. Como exemplo, a pessoa cega fica separada do mundo das percepções, das coisas, das cores, das formas. Deste modo, não há muito sentido em conversar se está claro ou escuro, se algo é belo ou não com ela. Porém, na situação do surdo, o mundo das percepções visuais é o seu mundo. Ele não fica separado. 0 surdo somente fica isolado do mundo das conversas orais, do diálogo sonoro, podendo entender o conteúdo das mesmas se souber fazer leitura labial. Essa relação é um caminho de dois sentidos, haja vista que ao mesmo tempo em que o surdo não consegue ouvir o homem oralizado, a pessoa ouvinte não consegue "ouvir" 0 surdo.

Pensando no Brasil especificamente, são aproximadamente 45 milhões de pessoas que possuem alguma necessidade especial, de acordo com levantamento de 2010 do Instituto Brasileiro de Geografia e Estatística (IBGE). Entre essas necessidades, destacam-se as auditivas, visuais, motoras e/ ou mentais. Ressalta-se que um quinto desta comunidade é formado por pessoas com algum grau de ou surdez.

A surdez, por sua vez, de acordo com Miglioli e Santos (2017), caracteriza-se como algo invisível, haja vista que não é perceptível visualmente quando a pessoa é classificada como um deficiente auditivo, somente em casos em que se utiliza algum aparelho auditivo ou comunique-se por meio da língua de sinais.

Em termos da lei do Decreto $n^{0} 5.626 / 05$ - art. $2^{\circ}$, as pessoas surdas são:

[...] por ter perda auditiva, compreende e interage com o mundo por meio de experiências visuais, manifestando sua cultura principalmente pelo uso da Língua Brasileira de Sinais Libras. A deficiência auditiva, por sua vez, é entendida como "perda bilateral, parcial ou total, de quarenta e um decibéis (dB) ou mais, aferida por audiograma nas frequências de $500 \mathrm{~Hz}$, $1.000 \mathrm{~Hz}, 2.000 \mathrm{~Hz}$ e $3.000 \mathrm{~Hz}$ (BRASIL, 2005, não paginado).

Contudo, nesta investigação será empregado o termo "surdo", ao invés de deficiente auditivo, em concordância com o conceito do decreto 5.626, de 22 de dezembro de 2005. Esse decreto declara: "pessoa surda aquela que, por ter perda auditiva, compreende e interage com o mundo por meio de experiências visuais, manifestando sua cultura principalmente pelo uso da Língua Brasileira de Sinais - LIBRAS” (BRASIL, 2005, não paginado).

Dentro dessa linha de compreensão, Miglioli e Santos (2017) elucidam algo importante. Os referidos autores enfatizam que na área da pesquisa sobre surdez, a nomenclatura "deficiente auditivo" é utilizada para os indivíduos com surdez pós-linguística, ou seja, que tiveram perda auditiva após 
serem oralizados. Por outro lado, o termo "surdo" é usado para pessoas com surdez pré-linguistica, ou seja, para indivíduos que tiveram perda de audição antes da oralização. Sendo assim, é nesse segundo grupo o maior uso de utilizadores da língua de sinais.

Pessoas surdas ou com deficiência auditiva, costumam definir-se de modo diferente a outros indivíduos com tipos distintos de deficiências físicas. A comunidade surda percebe sua identidade enquanto plural. Para Rosa (2012, p. 23) “não há modelo para a identidade do sujeito surdo; a identidade sofrerá modificações de surdo para surdo em vista de suas representações históricas, sociais e visuais". Strobel (2006) aponta para o aspecto cultural ou sociolinguístico e não restringe o grupo a uma limitação para identificar determinado nível de decibéis. Para além do fenômeno físico há uma construção cultural em que a língua exerce um papel importante na construção da identidade dos surdos. Para Gesser (2009, p. 294) "é impossível estudar a identidade surda fora do seu contexto social, ocasião em que a língua exerce a função de veículo de relações sociais". Para a pesquisadora Quadros (2002) a cultura surda é multifacetada, mas apresenta a especificidade de ser visual.

Campello (2008) aponta uma multiplicidade de identidades para este grupo indo do deficiente auditivo, surdos oralizados, aos surdos. Para os sujeitos surdos a autora (pesquisadora surda)

A experiência da visualidade produz subjetividades marcadas pela presença da imagem e pelos discursos viso-espaciais provocando novas formas de ação do nosso aparato sensorial, uma vez que a imagem não é mais somente uma forma de ilustrar um discurso oral. 0 que captamos sensorialmente pelos olhos é apenas uma pista que é enviada aos sistemas neuroniais e, posteriormente, esses dados, através de operações mais complexas informam nosso cérebro, produzindo sentido do que estamos vendo. Por isso, as formas de pensamento são complexas e necessitam a interpretação da imagem-discurso. Essa realidade implica resignificar a relação sujeito-conhecimento principalmente na situação de ensinar e aprender (CAMPELLO, 2008, p 22).

Corroborando esse raciocínio, para Sá (2002), o surdo:

[...] é alguém que vivencia um déficit de audição que o impede de adquirir, de maneira natural, a língua oral / auditiva usada pela comunidade majoritária e que constrói sua identidade calcada principalmente nesta diferença, utilizando-se de estratégias cognitivas e de manifestações comportamentais e culturais diferentes da maioria das pessoas que ouvem

Considerando a importância da visualidade na comunicação dos surdos e os avanços de comunicação imagética com as novas tecnologias podemos perceber atualmente expressiva inserção de surdos nos ambientes informacionais digitais. Segundo Caldas (2012, p. 145)

[...] a internet trouxe inúmeras mudanças no que diz respeito à comunicação e acesso a informações [...]. No caso dos surdos, a possibilidade de registro visual, a língua de sinais sendo registrada em vídeo e declarando a essência deste movimento [...] devem se apropriar deste instrumento incluindo em seu currículo a tecnologia como importante sustentação da construção de nosso movimento 
Demonstrando, dessa forma, um caminho ainda por ser estudado sobre as comunidades de surdos existentes e de que forma apropriam-se das informações na internet. Acerca desse cenário Corradi (2007, p. 100) menciona que:

\begin{abstract}
A web surge como mais um ambiente digital que pode ampliar as oportunidades de acesso aos conteúdos informacionais; intensificar o contato de Surdos e ouvintes por meio da Língua de Sinais, com diferentes culturas surdas e ouvintes; democratizar 0 acesso às informações registradas e disponibilizadas; preservar e disseminar as culturas surdas, as literaturas, 0 teatro e 0 cinema dentre outras manifestações, por meio de documentos em diferentes formatos hipermídia.
\end{abstract}

A internet, então, é um importante espaço para pessoas surdas, uma vez que, além de prover um protocolo de comunicação acessível e uma interface penetrante, ela também viabiliza que indivíduos com necessidades especiais se apropriarem de um papel, que não foi pensado anteriormente como exequível, de agentes em uma rede de informação global (ALVES, 2014).

Ratificando essa vocação da internet, a web é amplamente utilizada por surdos. Entre os nove milhões de brasileiros com perda auditiva (IBGE, 2010), aproximadamente $68,2 \%$ acessam a internet diariamente (SCHWARZ; HABER, 2006). Em contrapartida, somente 40\% da população brasileira tida como ouvinte usa a internet, proporção inferior se comparada ao uso da população com surdez (IBGE, 2010).

\title{
3 REPOSITÓRIOS DIGITAIS EM VOGA
}

Ao serem abordadas as questões contemporâneas dos repositórios digitais, torna-se necessário compreender quais fatos foram importantes para a atual configuração desses sistemas.

Sobre essa realidade, historicamente, Meadows (1999) retrata que as informações no contexto da ciência eram circuladas por meio de cartas entre grupos de pesquisadores. Esse fator limitava 0 acesso da sociedade ao que se estava sendo gerado cientificamente. Porém, o primeiro passo foi dado em meados do século XVII, surgem os primeiros periódicos científicos com o objetivo de registrar as informações de inovações, descobertas e avanços em temas específicos da ciência. Deste modo, construiu-se, a partir desse momento, a comunicação científica formal.

Alguns séculos passaram até que os periódicos científicos entrassem em "crise global". Isso se iniciou a partir do final da década de 1980 e primeira metade da década de 90 . Os altos preços das assinaturas, a dificuldade nas aquisições de materiais científicos pelas bibliotecas e 0 dificultoso acesso dos usuários foram fatores agravantes para crise. Consequentemente, isso prejudicou o avanço de investigações científicas assim como o progresso da ciência como um todo. 
Porém, com 0 avanço exponencial das Tecnologias de Informação e Comunicação (TICs) observada a partir da década de 1990, surge um ponto positivo para 0 avanço das comunidades científicas, mesmo com a crise dos periódicos já em curso. 0 crescimento eminente da internet foi um ponto decisivo para um acesso ao conhecimento de forma mais eficaz e sem barreiras geográficas.

Castells (2003) menciona que a Internet é o tecido de nossas vidas, pois ela representa uma estreita ligação entre os seres humanos e a web através de redes de comunicação. Neste sentido, a metáfora do tecido explica o que significa a Internet: um complexo emaranhado de fios imaginários ligando as pessoas, por meio de troca de informações.

Em concordância com esse horizonte, Turner e Muñoz (2002, p. 15), afirmam que: “[...] os gestos definiram a estrutura social do Homem de Neanderthal. A escrita e a pintura definiram 0 Cromagnon, e o bit definirá o ser Infosocial".

Além disso, o uso intensivo das tecnologias da informação fortaleceu o fenômeno da produção e disseminação informacional, fato este mais evidente na Internet e nos serviços a ela associados. (TAKAHASHI, 2000).

Assim como a comunicação passou por diversas transformações no transcurso histórico da humanidade, a Internet também se modificou e a quantidade de usuários aumentou significativamente. Em outras palavras, a internet surgiu de um artifício de uso militar para mecanismos de uso cotidiano que abrange várias esferas da vida humana, atingindo grande parte da população mundial.

A comunicação, por sua vez, foi grandemente afetada pela evolução da Internet, uma vez que outrora eram necessárias várias horas para transmitir uma notícia ou esperar semanas para que uma correspondência chegasse ao seu destino. Com os novos mecanismos de comunicação digitais, a disseminação de informações em tempo real ganhou novas possibilidades.

Neste limiar, Leite (2009) destaca que pesquisadores de vários países se reuniram e iniciaram um movimento global em direção ao acesso aberto à informação científica, utilizando a internet como uma forte ferramenta para esse fim. Os novos recursos tecnológicos e informacionais impulsionam a iniciativa de arquivos abertos (Open archives).

Dentre os objetivos dos repositórios digitais pode ser enfatizado o atendimento da iniciativa da Open Acess, conhecida no Brasil como o Movimento do Acesso Aberto. Uma ação que teve gênese na cidade de Budapeste pelo Open Society Institute (OSI), no ano de 2001. 0 Movimento do Acesso Aberto possibilita o incentivo da literatura científica, com o objetivo dar acesso a produções científicas em um modo aberto e livre de custos financeiros. 
Conforme o documento da BUDAPEST OPEN ACCESS INITIATIVE (2001, não paginado):

0 acesso aberto é um bem público que possibilita a distribuição eletrônica das redes de literatura periódica e revisada por pares completamente gratuitas sem restrições de acesso por toda a comunidade científica. Retirar as barreiras de acesso a essa literatura acelerará a investigação, enriquecerá a educação, compartilhará o aprendizado dos ricos com os pobres e dos pobres com os ricos. Essa literatura se fará tão útil quanto possível e estabelecerá as bases para unir a humanidade para a busca do conhecimento.

Nesse contexto, no Brasil em especial, o Instituto Brasileiro de Informação em Ciência e Tecnologia (IBICT) lança um manifesto, no ano de 2005, em apoio ao acesso livre à informação científica, conforme retrata Chalhub (2012, p. 162):

Este documento visa promover, em consonância com o paradigma do acesso livre à informação, o registro e a disseminação da produção científica brasileira, além de estabelecer uma política nacional de acesso livre à informação, buscando apoio da comunidade científica em prol desse movimento.

Desse modo, surgem propostas para implantação e institucionalização dos repositórios digitais no Brasil com o intuito de promover a produção científica nacional.

De acordo com o relato de Kuramoto (2006), o Brasil teve um expressivo aumento no número de repositórios digitais. Isso favoreceu o país a alcançar o quarto lugar entre os países com maior número de repositórios institucionalizados e ativos. 0 incentivo promovido pelo IBICT foi fator motivador desse cenário, com a abertura da "Manifestação Brasileira de Apoio ao Acesso Livre à Informação Científica". Esse projeto está ligado à lei 1.120/2007 que determina a elaboração de repositórios digitais para instituições de ensino e pesquisa. Essa iniciativa visava, conforme Ribeiro e Vidotti (2009, p. 107) a: "[...] promover o acesso livre à informação científica através da proposta de criação de repositórios digitais por parte das instituições de ensino superior e no depósito de artigos produzidos pela comunidade acadêmica nesses ambientes informacionais."

Conceitualmente, os repositórios digitais, de acordo com Leite (2009), são os sistemas de informação que têm por objetivo armazenar, preservar, divulgar e possibilitar o acesso à produção intelectual de comunidades científicas. Ressalta-se, ainda, que os repositórios digitais usam tecnologias abertas, possibilitando, desse modo, uma utilização global através de provedores nacionais e internacionais.

Os repositórios digitais podem ser classificados em três categorias, conforme Leite (2009) pontua a seguir: 
a) Repositórios temáticos: dizem respeito a um conjunto de trabalhos de umaárea do conhecimento específica, ou seja, particulariza a produção intelectual em função das áreas temáticas do conhecimento;

b) Repositórios de Teses e Dissertações: sistematizam de modo exclusivo as teses e dissertações defendidas nos programas de pós-graduação das diversas áreas do conhecimento;

c) Repositório institucional: destinados a organizar a produção intelectual de uma instituição, como por exemplo, universidades e centros de pesquisa.

Quanto aos softwares utilizados para a construção de repositórios digitais, destacam-se algumas plataformas gratuitas, como o Dspace, Fedora e Eprints, como os mais utilizados em nível global para essa finalidade. No Brasil, o mais usado é o Dspace, que possui como principais características, de acordo com Viana, Márdero Arellano, Shuntaku (2005, p. 9):

a) ser um software livre;

b) ter arquitetura de software simples e eficiente;

C) usar tecnologia de ponta;

d) ser direcionado para o acesso aberto;

Intencionalmente implementado para servir de repositório. No Dspace os dados estão organizados de forma a refletir a estrutura da instituição e se organizam em coleções.

Tratando-se dos documentos suportados para armazenamento nos repositórios digitais, eles permitem o depósito de tipos e formatos documentais diversos, tais como: artigos científicos, teses e dissertações, relatórios de pesquisa, registros administrativos, livros, notícias de jornais, páginas da Web - em formatos diversos.

\section{REPOSITÓRIO HUET COMO AMBIENTE DIGITAL BILINGUE}

Para essa investigação, tem-se o caso de um repositório digital que trabalha com materiais destinados a surdos e pessoas com que trabalham com educação de surdos. Sobre esse repositório, nota-se uma oportunidade ímpar voltada a esse público, tornando-os sujeitos importantes também no ambiente digital.

0 Repositório Digital Huet se intitula assim em homenagem ao professor surdo Ernest Huet, um francês que veio ao Brasil no ano de 1855. Ele foi o responsável por elaborar um relatório ao 
imperador Dom Pedro II com o objetivo de fundação de um instituto (HUET, 1855)5. A partir dessas recomendações, em 26 de setembro de 1857 o imperador inaugura o "Imperial Instituto dos SurdosMudos", atualmente "Instituto Nacional de Educação de Surdos" (INES).

0 repositório Digital Huet teve seu lançamento em novembro de 2017. Ele foi desenvolvido e é mantido pelo INES. Esse ambiente digital reúne, armazena, sistematiza e preserva objetos sobre educação de surdos em formatos diversos (textos, vídeos, imagens, aulas, produções artísticas e culturais etc.) com a proposta de dar acessibilidade a esses tipos de conteúdos visando a educação de surdos. Ele é povoado tanto pelo instituto como por outras instituições, haja vista que a alimentação do sistema é feita a partir do compartilhamento de materiais.

Um diferencial desse repositório é a tradução de seu conteúdo para a LIBRAS, tornando-se 0 primeiro ambiente informacional do gênero no Brasil com essa característica.

0 uso da língua de sinais é um dos principais meios de comunicação utilizados por pessoas surdas, é uma língua visual que mescla características linguísticas e culturais, como qualquer outra língua. Os primeiros registros de uso de língua de sinais foram na Europa, Espanha e França, no século XVII. Durante muitos séculos essas pessoas foram limitadas a não se expressarem, pois não tinham uma língua natural, além dos sinais não terem sido aceitos pelos ouvintes em um primeiro momento. Assim, com o transcurso histórico, as pessoas surdas foram desenvolvendo em cada país a sua própria língua de sinais (SILVA; SANTOS; RODRIGUES, 2011)

No Brasil, há a utilização da LIBRAS, oficializada por meio da Lei 10.436 em 2002. Atualmente é regulamentada pelo Decreto 5.626 de 2005. Dentre as providências que a legislação delimita, destacamse: a sua inclusão no currículo escolar, a sua utilização e disseminação em conjunto com a língua portuguesa possibilitando o acesso de surdos à educação e garantia do direito à educação.

Dessa forma, Andrade (2007) relata que a LIBRAS foi um ponto positivo para a vida dos surdos no Brasil, pois proporcionou um artifício transformador da linguística e cognição desse grupo.

Nesse cenário, observa-se a maior integração do surdo na sociedade ouvinte. A respeito desse fato, Strobel (2006) coloca a extrema importância da identificação do surdo como "surdo".

0 repositório Huet utiliza o software livre DSpace. Quanto à organização do Repositório, ele está dividido em quatro comunidades: Áreas do conhecimento, Arquivo histórico, Diversão e lazer,

5 Carta original em francês com tradução para Libras disponível em: http://repositorio.ines.gov.br/ilustra/bitstream/123456789/185/6/ Relatorio_ao_rei.mp4 
Jornalismo. Cada uma dessas comunidades possui subcomunidades ou coleções que especificam 0 tipo de materiais disponibilizados, a saber:

a) Áreas do conhecimento - Ciências biológicas, Ciências da Saúde, Ciências Exatas, Ciências Humanas, Ciências Sociais Aplicadas, Linguística, Letras e artes;

b) Arquivo histórico - Acervo histórico externo, acervo histórico INES;

c) Diversão e lazer - Esportes, humor, infantil, produções culturais;

d) Jornalismo - Documentários, jornais, reportagens

Em modo quantitativo, atualmente o Repositório Huet possui, conforme 0 Gráfico 1, 0 total de 544 objetos digitais depositados. Os dados foram coletados em novembro de 2018.

Gráfico 1 - Comunidades do repositório digital Huet

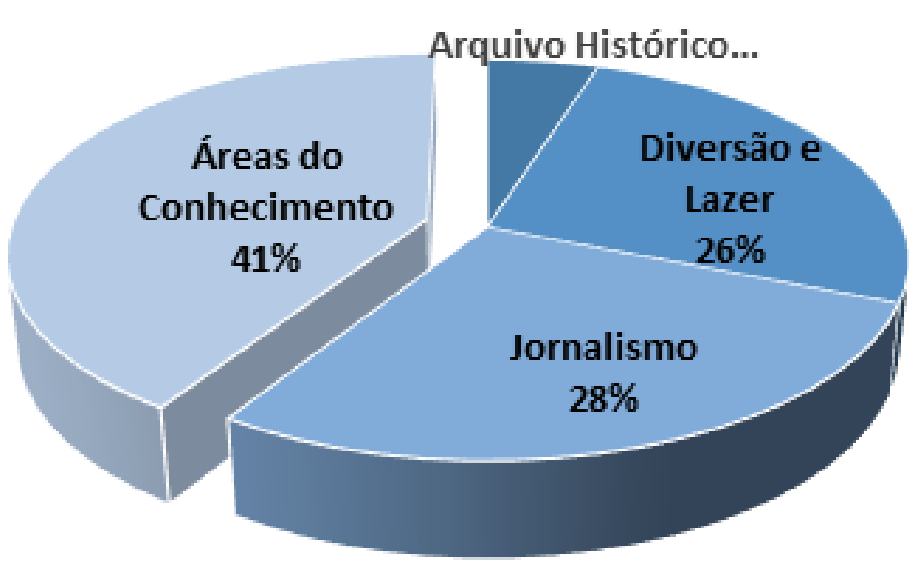

Fonte: Dados da pesquisa (2018)

Vale ressaltar, conforme 0 Gráfico 1, que a maior parte do acervo depositado nesse ambiente digital são referentes a "áreas de conhecimento", que subdividem em seis coleções (grupos): Ciências Biológicas; Ciências da Saúde; Ciências Exatas; Ciências Humanas; Ciências Sociais Aplicadas; Linguística, Letras e Artes. Cada uma dessas coleções traz documentos sobre a realidade do surdo em contextos mais específicos, principalmente na área da educação.

Dentre as demais comunidades, ressalta-se a grande presença de materiais multimídias que retratam temáticas diversas, desde o esporte, humor e a história do surdo no Brasil. Como um dos materiais mais peculiares verificados, abre-se espaço para o programa "Café com Pimenta", na qual 0 
usuário tem acesso a um programa apresentado pelo professor e pesquisador surdo Nelson Pimenta, que possui experiência no mundo artístico. 0 programa convida personalidades para um bate-papo regado a café, humor, conteúdo e temas relevantes, com destaque para temáticas que envolvam LIBRAS. 0 Repositório Huet não é somente um espaço de cunho científico, ele também congrega diversão e cultura no mesmo espaço, possibilitando ao surdo um convívio digital mais interativo para suas demandas diversas.

Na figura 1 pode ser observada a página inicial do Repositório Huet, com destaque para a intérprete de Libras ${ }^{6}$ na área central possibilitando ao usuário passar o cursor por cada parte textual da página para que as informações sejam traduzidas, facilitando acesso à informação procurada com eficácia.

Figura 1 - Página inicial do Repositório Huet

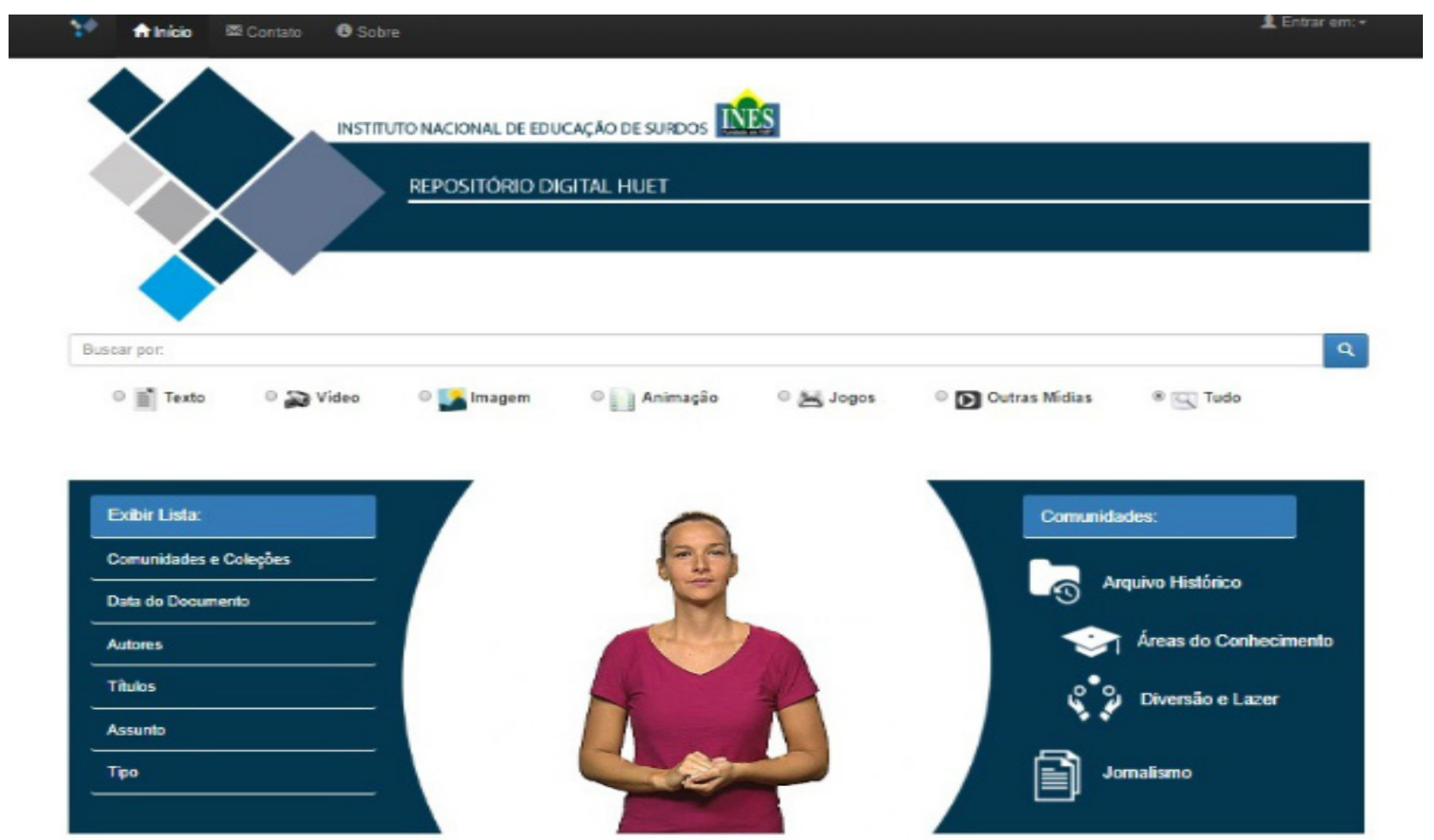

Fonte: REPOSITÓRIO, 2018

Além da página inicial do repositório, o usuário também possui o auxílio da tradução nas páginas subsequentes, como pode ser visto na Figura 2:

6 Professora surda do INES 
Figura 2 - Auxílio de tradução em outras páginas do repositório Huet

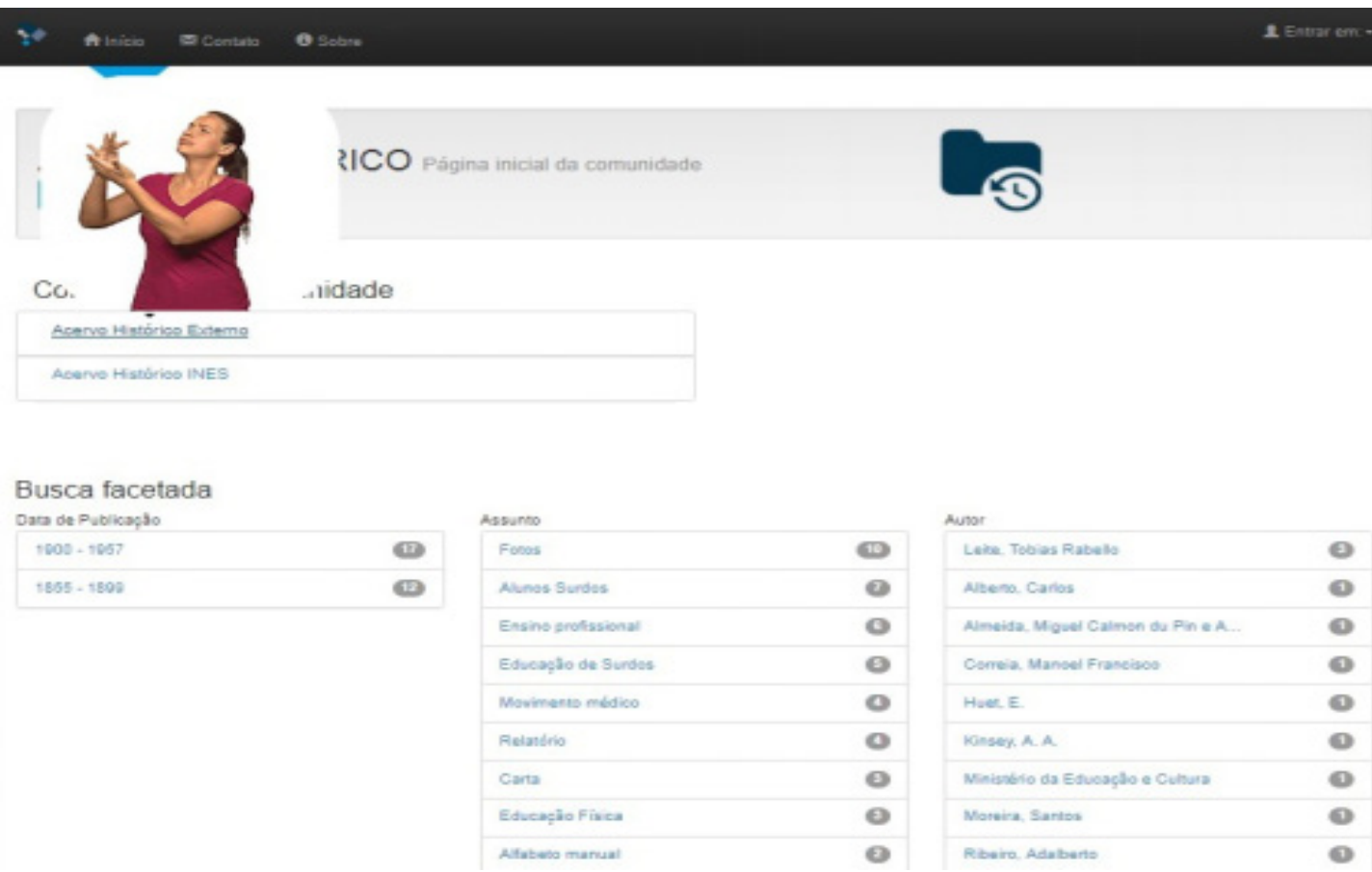

Fonte: REPOSITÓRIO, 2018

A equipe envolvida com 0 desenvolvimento e manutenção do repositório Huet apresentam-se em LIBRAS no link “Sobre”, organizados conforme suas funções: Coordenador do Núcleo de Educação Online; Coordenador do Curso de Pedagogia Bilíngue Online; Coordenadora do Repositório HUET; Técnicos em Tecnologia da Informação; Assistentes Administrativos; Equipe de Tradução e Equipe de vídeo, nesse espaço do repositório o usuário tem acesso, sobretudo, aos currículos do grupo.

Esse repositório apresenta-se como um canal importante para a mediação entre os usuários e as informações que necessitam, uma vez que possibilita a recuperação e disseminação de objetos de aprendizagem para alunos surdos e ouvintes em cursos online e presenciais em níveis diversos de ensino.

Diante disso, tendo em vista 0 aspecto da mediação, parte-se da compreensão que as evoluções das tecnologias da informação, mais especificamente em relação a Internet, propiciam novos paradigmas em atividades mediadoras, ou seja, o paradigma do acesso à informação, em contrapartida ao paradigma de posse da informação (SILVA; LOPES, 2011).

No Repositório em estudo são vistas algumas funcionalidades bilíngues como elementos de interface hipermídia. Neste momento, vale destacar que a utilização da LIBRAS em ambiente digital 
é tida como uma condição de acesso a usuários surdos sinalizadores. Porém, como Corradi (2007, p. 164) menciona: "Todavia, na perspectiva bilíngüe da surdez há a valorização da Língua de Sinais como natural ao Surdo e o português (oral ou escrito) como segunda língua, aspectos que devem ser mensurados no desenvolvimento de ambientes digitais inclusivos."

Os surdos necessitam do desenvolvimento de ambientes informacionais digitais estruturados em uma arquitetura universal, não exclusivos e excludentes.

0 caso do repositório Huet traz à tona um fato interessante do atual contexto da internet em que cada vez mais pessoas têm acesso a um "mundo de informações". Isso possibilita que os sistemas de informação e comunicação sejam desenvolvidos de modo mais amigáveis. Além disso, há uma melhor autonomia e independência para os usuários diversos. 0 exemplo do ambiente digital aqui enfatizado mostra as possibilidades para construção de espaços inclusivos, funcionais, visíveis e navegáveis por usuários com características diversas, a exemplo, os usuários surdos.

Em relação a esse repositório digital, vê-se a sua importância para análises em acessibilidade digital de surdos. Vale ressaltar, que algumas alterações e revisões em sua estrutura possam estar em curso, devido ao seu pouco tempo de implantação. Alterações e revisões essas no que tange, principalmente, ao olhar bilíngue, à arquitetura do ambiente e as condições de acesso e uso com caráter digital inclusivo.

\section{CONSIDERAÇÕES FINAIS}

A Internet é um verdadeiro fenômeno da comunicação contemporânea, assim como também de repositório informacional. Porém ela é um território em constante crescimento. Esse território carece de estratégias diversas para atender a públicos distintos.

Gestão de ambientes informacionais digitais sem planejamento, dificulta a navegação do usuário, dado que ele pode ficar perdido em meio ao "mar de dados". Visando a atender uma organização da informação de modo mais eficaz, foram desenvolvidas estratégias para tal contexto, principalmente no que diz respeito aos repositórios digitais, como ferramentas para a gestão e preservação da produção científica de instituições ou em temáticas específicas.

0 caso do Repositório Digital Huet mostra um exemplo do bom uso de instrumentos digitais para 0 atendimento de necessidades de grupos peculiares. Ao atender a usuários surdos, observase que os profissionais envolvidos na construção de ambientes digitais inclusivos devem sempre 
levantar questionamentos sobre acessibilidade para aprimoramento constante desses ambientes por eles gerenciados. Essa realidade vai muito além de somente incluir surdos através de suas vertentes sensoriais e linguísticas em ambientes digitais, para além disso, devem possibilitar autonomia e experiências agradáveis para o encontro dos conteúdos que estes almejam.

\section{REFERÊNCIAS}

ALVES, S. M. C. Apropriação da informação por surdos no ambiente web à luz da Ciência da Informação. Rio de Janeiro, 2014. 113f. Dissertação (Mestrado em Ciência da Informação) Programa de Pós-Graduação em Ciência da Informação, Instituto Brasileiro de Informação em Ciência e Tecnologia / Escola de Comunicação, Universidade Federal do Rio de Janeiro, Rio de Janeiro, 2014. Disponível em: https://bit.ly/2HLSfcl. Acesso em: 15 abr. 2018.

ANDRADE, C. F. C. Um novo olhar sobre a inclusão do surdo: os alicerces legais que permeiam esse processo. Educação Temática Digital, Campinas, v. 9, n. 1, dez. 2007.

BRASIL. Constituição (2005). Decreto n ${ }^{0}$ 5626, de 22 de dezembro de 2005. Regulamenta a Lei no 10.436, de 24 de abril de 2002, que dispõe sobre a Língua Brasileira de Sinais - Libras, e 0 art. 18 da Lei no 10.098, de 19 de dezembro de 2000. Brasília, DF, 22 dez. 2005. Disponível em: https://goo. gl/5aaNLj. Acesso em: 04 abr. 2018.

BUDAPESTE Open Access iniciative. 2001. Disponível em: http://www.budapest openaccessinitiative. org/. Acesso em: 05 maio 2018.

CALDAS, A. L. P. Movimento surdo: identidade, língua, cultura. In: PERLIN, Gladis; STUMPF, Marianne. (org.) Um olhar sobre nós surdos: leituras contemporâneas. Curitiba: Editora CRV, 2012.

CAMPELLO, A. R. S. Aspectos da visualidade na educação de surdos. 2008. 244 f. il. Tese (Doutorado em Educação)- Centro de Ciências da Educação. Universidade Federal de Santa Catarina, Florianópolis, 2008. Disponível em: http://repositorio.ines.gov.br/ilustra/bitstream/123456789/277/1/ Campello\%202008\%20tese.pdf. Acesso em: 05 out. 2018.

CASTELLS, M. A galáxia da Internet: reflexões sobre a Internet, os negócios e a sociedade. Rio de Janeiro: Jorge Zahar, 2003.

CHALHUB, T. Ações para implantação de repositórios institucionais em universidades públicas no Estado do Rio de Janeiro, Informação \& Sociedade., João Pessoa, v. 22, n. 2, p. 115-126, maio/ago. 2012

CORRADI, J. A. M. Ambientes informacionais digitais e usuários surdos: questões de acessibilidade. 2007. 214 f. Dissertação (Mestrado) - Curso de Ciência da Informação, Faculdade de Filosofia e Ciências, Universidade Estadual Paulista, Marília, 2007.

GESSER, A. Do patológico ao cultural na surdez: para além de um e de outro ou para uma reflexão crítica dos paradigmas. In: QUADROS, Ronice Müller de; STUMPF, Marianne Rossi (org.). Estudos 
Surdos IV. Petrópolis: Arara Azul, 2009. Disponível em: http://repositorio.ines.gov.br/ilustra/ bitstream/123456789/672/1/Quadros_Ronice_Estudos-surdos-IV.pdf . Acesso em: 05 out. 2018.

HUET, E. Rapport à I'Empéreux. 22, junho de 1855. Carta manuscrita. Disponível em: http:// repositorio.ines.gov.br/ilustra/bitstream/123456789/185/1/Relatorio\%20Huet\%20\%281\%29.pdf . Acesso em: 05 out. 2018.

IBGE. População residente, por tipo de deficiência, segundo a situação do domicílio e os grupos de idade - Brasil - 2010. Rio de Janeiro: IBGE, 2010. Disponível em: https://goo.gl/2mDV3p . Acesso em: 04 abr. 2018.

KURAMOTO, H. Informação científica: proposta de um novo modelo para o Brasil. Ciência da Informação, v. 35, n. 2, p. 91-102, 2006.

LEITE, F. C. L. Como gerenciar e ampliar a visibilidade da informação científica brasileira: repositórios institucionais de acesso aberto. Brasília, DF: IBICT, 2009.

MEADOWS, A. J. A comunicação científica. Brasília: Brinquet de Lemos, 1999.

MIGLIOLI, S.; SANTOS, G. A. Acessibilidade e serviços inclusivos para minorias sociais: a biblioteca do Instituto Nacional de Educação de Surdos. Revista ACB: Biblioteconomia em Santa Catarina, Florianópolis, v. 22, n. 1, p. 136-149, dez./mar., 2017.

QUADROS, R. 0 tradutor e intérprete da Língua Brasileira de Sinais e Língua Portuguesa. Brasília: MEC/SEESP. 2002. Disponível em: http://portal.mec.gov.br/seesp/arquivos/pdf/tradutorlibras.pdf . Acesso em: 05 out. 2018.

REPOSITÓRIO Digital Huet. 2018. Elaborado pelo Instituto Nacional de Educação de Surdos. Disponível em: <http://repositorio.ines.gov.br/ilustra/>. Acesso em: 16 out. 2018.

RIBEIR0, 0. B; VIDOTTI, S. A. B. G. Otimização do acesso à informação científica: discussão sobre a aplicação de elementos da arquitetura da informação em repositórios digitais. BIBLOS: Revista do Instituto de Ciências Humanas e da Informação, v. 23, n. 2, p. 105-116, 2009.

ROSA, A. S.; CRUZ, C. C. C. Internet: fator de inclusão da pessoa surda. Rev. Online da Bibl. Prof. Joel Martins, Campinas, v.2, n.3, p. 38-54, jun. 2001.

ROSA, E. F. Identidades surdas: o identificar do surdo na sociedade. In: PERLIN, Gladis; STUMPF, Marianne. (org.) Um olhar sobre nós surdos: leituras contemporâneas. Curitiba: Editora CRV, 2012.

SÁ, N. R. L. Cultura, poder e educação de surdos. Manaus: EDUA, 2002.

SCHWARZ, A.; HABER, J. População com deficiência no Brasil: fatos e percepções. São Paulo: FEBRABAN, 200

SILVA, E. L.; LOPES, M. A internet, a mediação e a desintermediação da informação, DataGramaZero, n. 2, v. 12, 2011.

SILVA, R. A.; SANTOS, R. N. M.; RODRIGUES, R. S. Estudo bibliométrico na base LISA: um enfoque nos artigos sobre os surdos. Em Questão, Porto Alegre, v. 17, n. 1, p. 283 - 298, jan./jun. 2011. 
STROBEL, L. K. A visão histórica da in(ex)clusão dos surdos nas escolas. Educação Temática Digital, Campinas, v. 7, n. 2, jun. 2006.

TAKAHASHI, T. (org.). Sociedade da informação no Brasil: livro verde. Brasília, DF: Ministério da Ciência e Tecnologia, 2000.

TURNER, D.; MUÑOZ, J. Para os filhos dos filhos de nossos filhos: uma visão da sociedade internet. São Paulo: Summus, 2002.

VIANA, C. L. M; MÁRDERO ARELLANO, M. A.; SHINTAKU, M. Repositórios institucionais em Ciência e Tecnologia: uma experiência de customização do Dspace. In: PROCEEDINGS SIMPOSIO INTERnACIONAL DE BIBLIOTECAS DIGITAIS, 3., 2005, São Paulo. Anais... São Paulo. 